\title{
Klinik Öncesi Bir Grup Diş Hekimliği Öğrencilerinin Dental Travmaya Yaklaşımı: Bir Anket Çalışması
}

\author{
Bilal Özmen(0000-0002-4435-288X) ${ }^{\alpha}$, Sevcan YIImaz(0000-0001-9660-4228) ${ }^{\beta}$, Zeynep Kaya(0000-0003-1576-9560) ${ }^{\alpha}$,
}

Hatice Zehra Bodur Güney(0000-0001-7416-3177) ${ }^{\vee}$

Selcuk Dent J, 2021; 8: 703-707 (Doi: 10.15311/selcukdentj.778584)

Basvuru Tarihi: 10 Ağustos 2020 Yayına Kabul Tarihi: 09 Aralık 2020

\section{Öz}

Klinik Öncesi Bir Grup Diş Hekimliği Öğrencilerinin Dental Travmaya Yaklaşımı: Bir Anket Çalışması

Amaç: Ebeveynlerin ve öğretmenlerin dental travmalara yaklaşımlarını değerlendiren çalışmalar mevcuttur, fakat dental travma konusunda eğitim almamış diş hekimliği öğrencilerinin dental travmalara yaklaşımları henüz değerlendirilmemiştir. Bu çalışmada dental travma eğitimi almamış klinik öncesi diş hekimliği öğrencilerinin dental travma bilgi düzeylerinin ölçülmesi amaçlanmıştır.

Gereç ve Yöntemler: Bu çalışmaya bir diş hekimliği fakültesinde dental travma eğitimi almamış ve ankete katımayı kabul eden birinci, ikinci ve üçüncü sınıf diş hekimliği öğrencileri dahil edildi. Öğrencilerin dental yaralanmalara yaklaşımlarının değerlendirilebilmesi için daha önce uygulanmış ve geçerliliği bulunan anketler modifiye edilerek kullanıldı. On iki soru içeren bir anket, doldurmaları için öğrencilere verildi. Sonuçlar yüzde olarak hesaplandı. Verilerin analizinde Ki-kare testi kullanıldı.

Bulgular: 364 öğrenciden 277'si ankete katılmayı kabul etti. Bu öğrencilerden 108'i (\% 39) birinci sınıf, 85'i (\% 30.7) ikinci sınıf ve 84 'ü (\% 30.3) üçüncü sınıftı. Sadece 55 (\% 19.8) öğrenci dental yaralanmalar hakkında bilgi sahibiydi. Bu öğrencilerden 31'i bilgiyi diş hekiminden almıştı. Öğrencilerin \% 56.7'si avulse daimi dişi reimplante edeceğini, \% 63.9'u süt dişini reimplante etmeyeceğini belirtti. Öğrencilerin \% 29.6'sı avulse bir dişin taşınmasında süt tercih ederken \% 23.4'ü taşıma için tükürük ya da ağız içerisini önerdi.

Sonuç: Diş hekimliği öğrencileri genellikle travmatik dental yaralanmalar hakkında doğru yaklaşımlara sahiptir fakat bazı yanlış ve eksik bilgileri de vardır.

\section{ANAHTAR KELIMELER}

Diş hekimliği öğrencileri, Travma, Bilgi

"Travma" sözcüğü eski Yunanca'dan köken almaktadır ve köken aldığı bu dilde yara anlamında, günümüzde ise yaşayan organizmada vücudun herhangi bir bölgesine kimyasal, mekanik, fiziksel ve psikolojik olarak gelebilen etki/etkiler olarak kullanılmaktadır. "Travmatik dental yaralanma" ise dişlerde kırılma ve/veya yer değiştirmeye, destek dokularda (dişeti, periodontal ligament, kemik) ayrılma ve ezilme ile sonuçlanan, akut ileti veya enerji boşalması olarak tanımlanır. ${ }^{1}$

\section{ABSTRACT}

Approach of A Group of Pre-Clinical Dentistry Students to Dental Trauma: A Survey Study

Background: There are studies evaluating the approach of parents and teachers to dental traumas, but dentistry students who have not been trained in dental trauma have not been evaluated yet. The aim of this study was to evaluate knowledge and attitudes of pre-clinical dental students who have not received dental trauma training, regarding to the dental trauma.

Methods: This study included first, second and third grade dentistry students who did not receive dental trauma training at a dentistry faculty and agreed to participate in the survey. In order to evaluate students' approaches to dental injuries, previously applied and valid questionnaires were modified and used. A questionnaire containing twelve questions was given to the students to fill. The results were calculated as a percentage. Chisquare test was used to analyze the data.

Results: 277 students from 364 agreed to participate in a questionnaire, of these $108(39 \%)$ were in first grade, $85(30.7 \%)$ were in second grade and $84(30.3 \%)$ were in third grade. Only $55(19.8 \%)$ subjects had received knowledge about dental injuries, with 31 of them being instructed by a dentist. $56.7 \%$ of the students chose to reimplant an avulsed permanent tooth but $63.9 \%$ of the students not preferred to reimplant an primary tooth. $29.6 \%$ of the students preferred milk for transporting an avulsed tooth and $23.4 \%$ suggested to transport in saliva or mouth.

Conclusion: Dental students generally had a right approach about traumatic dental injuries but they had got some false and incomplete knowledge.

\section{KEYWORDS}

Dental students, Trauma, Knowledge

Travmatik dental yaralanmalardan, hem süt dişleri hem de daimi dişler etkilenebilir. En çok etkilenen dişler; üst santral, lateral, alt santral ve lateral dişlerdir. Çenelere göre ise en çok üst çenede, sonra alt çenede ve en az hem alt hem de üst çenenin birlikte etkilendiği travmatik dental yaralanmalar gözlenmektedir. Süt dentisyonda travmatik diş yaralanmalarının görülme sıklığında erkekler ve kızlar arasında belirgin bir fark olmamasına rağmen, daimi dentisyonda, erkeklerde travmatik dental yaralanmalar daha sık

\footnotetext{
${ }^{\alpha}$ Ondokuz Mayıs Üniversitesi Diş Hekimliği Fakültesi Pedodonti AD, Samsun, Türkiye

$\beta$ Serbest Diş Hekimi, Tekirdağ, Türkiye

${ }^{\vee}$ Giresun Üniversitesi Diş Hekimliği Fakültesi Pedodonti AD, Giresun, Türkiye
} 
gözlenmektedir. Dental travma insidansının \% 11-60 arasında olduğu bildirilmektedir., ${ }^{2,3}$ Travmatik diş yaralanmalarının görülme sıklığı; çalışmaların yapıldığı ülkelere, çalışmaya dahil edilen grubun yaşına, cinsiyetine ve travmatik yaralanma tiplerine göre değişiklik göstermektedir. ${ }^{4-7}$ Risk nedenleri açısından yapılan incelemelerde günlük yaşam aktivitelerinin \% 38 , sporun $\% 31$, şiddetin $\% 12$, trafik kazalarının $\% 12$, iş kazalarının \% 5 ve diğer sebeplerin de $\% 2$ oranında travmatik dental yaralanmalara yol açtığı belirlenmiştir. $^{8}$

Travmatik dental yaralanmalarda kısa süre içerisinde yapılan müdahaleler prognozun daha başarılı olmasını sağlar. Çocuklarda diş ve diş eti dokularını ilgilendiren yaralanmalarda ilk müdahaleyi, yaralanmanın ciddiyetine ve meydana geldiği yere göre, evde aileler, okulda ise öğretmenler yapmaktadır. ${ }^{7,9}$ Yaralanmaların ciddi olduğu durumlarda, yaralanmalara ilk müdahale eden ve hastayı uzman hekime yönlendiren diş hekiminin tutumu önem kazanır. Ebeveynlerin ve öğretmenlerin dental travmalara yaklaşımlarını değerlendiren çalışmalar mevcuttur ${ }^{10-13}$, fakat dental travma konusunda eğitim almamış diş hekimliği öğrencilerinin dental travmalara yaklaşımları henüz değerlendirilmemiştir. Bu çalışmanın amacı dental travma dersi almamış diş hekimliği fakültesi birinci, ikinci ve üçüncü sınıf preklinik öğrencilerinin dental yaralanmalara yaklaşımlarının bir anketle değerlendirilmesidir.

\section{GEREÇ VE YÖNTEMLER}

Çalışma için Ondokuz Mayıs Üniversitesi Klinik Araştırmalar Etik Kurulu'ndan etik izni alındı. Bu çalışmada Ondokuz Mayıs Üniversitesi Diş Hekimliği Fakültesi'nde travmatik dental yaralanmalar dersini/eğitimini almamış birinci, ikinci ve üçüncü sınıf klinik öncesi öğrencileri yer almaktadır. Öğrencilerin dental yaralanmalara yaklaşımlarının değerlendirilebilmesi için daha önce tıp fakültesi öğrencilerine ${ }^{9}$ ve tıp hekimlerine, ilkokul öğretmenlerine ${ }^{13}$ ve ailelere ${ }^{10,11}$ uygulanan ve geçerliliği bulunan anketler modifiye edilerek kullanıldı. Öğrencilerin ankete katılıp katılmamaları tamamen gönüllülük esasına dayanmaktadır. Ankete katılmayı kabul eden öğrencilerin dental travmaya yaklaşımları dağıtılan bir anketle değerlendirildi (Tablo 1).

Sorulardan elde edilen cevaplar analiz edildi ve her bir sorunun cevabı yüzde olarak hesaplandı. Verilerin analizinde SPSS paket programı ve ki-kare testi kullanıldı. Anlamlılık düzeyi $p<0,05$ olarak belirlendi.

\section{Tablo 1.}

\section{Öğrencilere dağıtılan anket ve ankete verilen cevaplar}

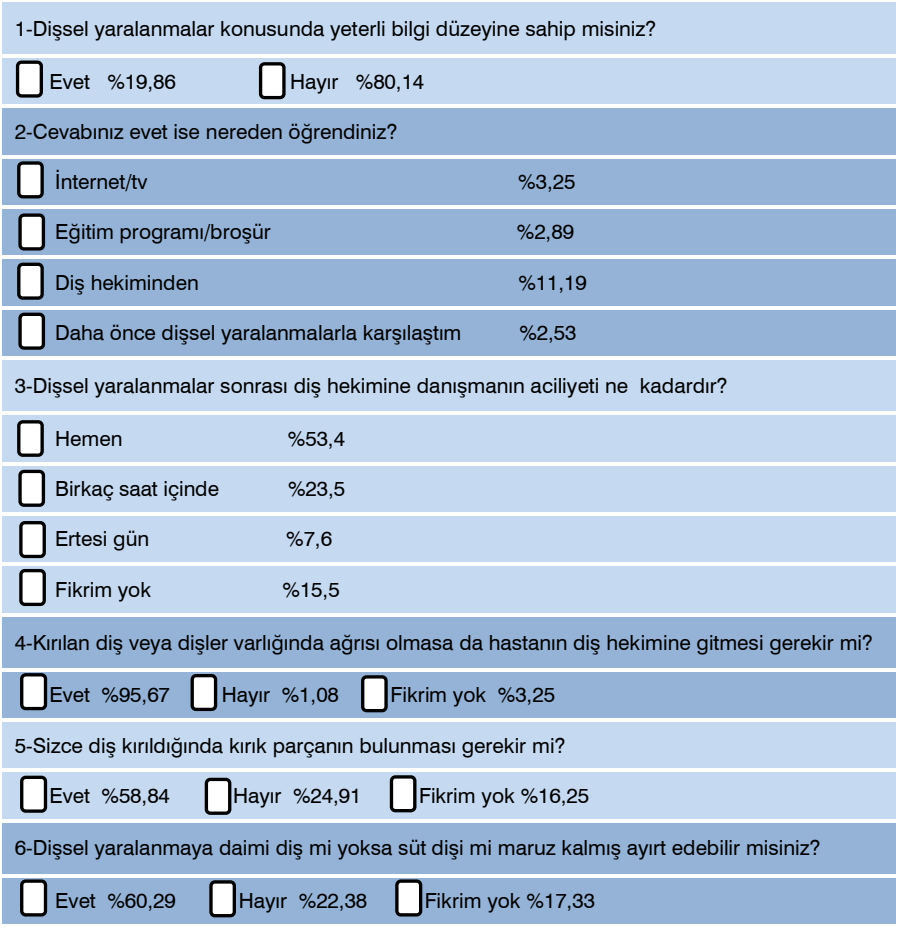

7-Daimi dişi yerinden tamamen çıkan bir hastada, dişi yerine yerleştirmeyi düşünür müsünüz? $\square$ Evet \%56,68 口Hayır \%29,24 DFikrim yok \%14,08

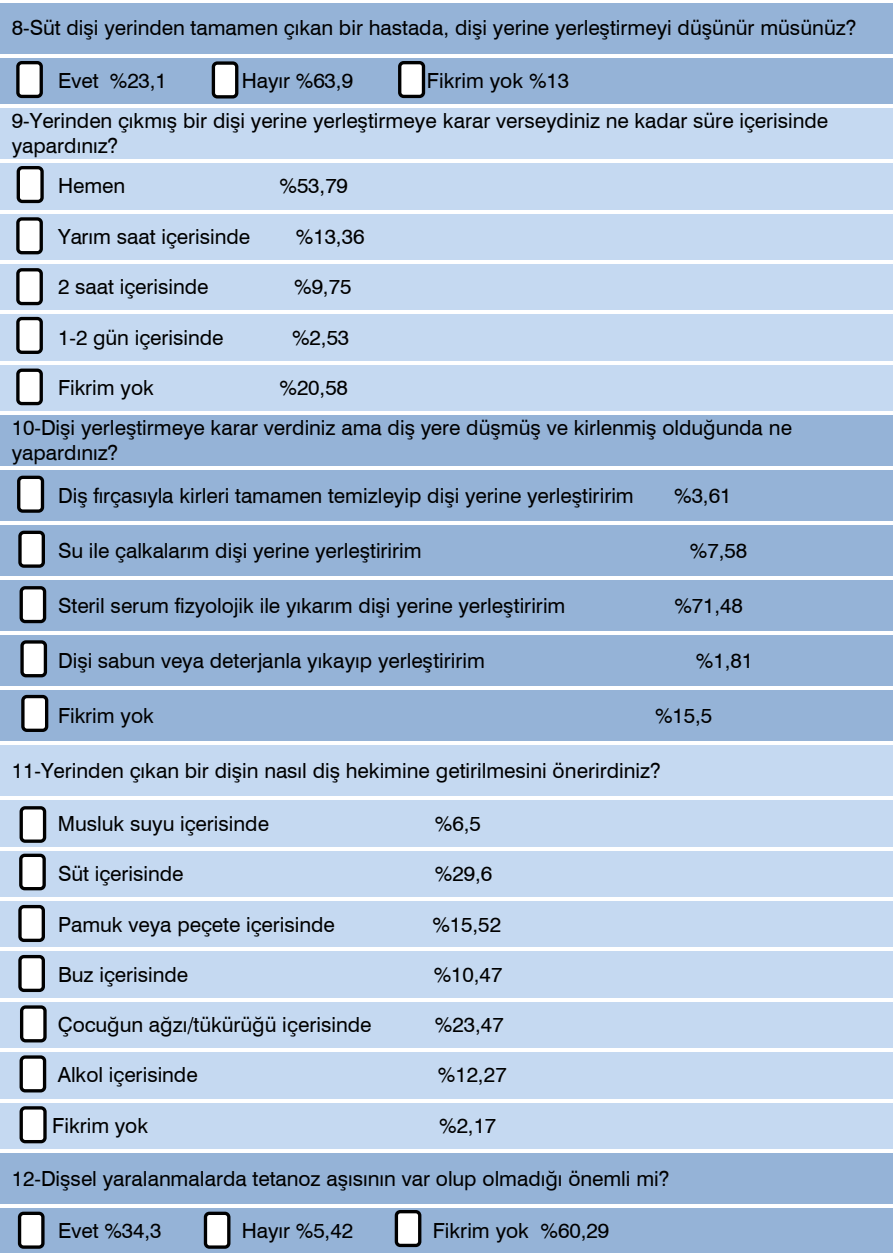




\section{BULGULAR}

Çalışmaya dahil olan ve olmayan öğrenci sayıları Tablo 2'de gösterilmiştir.

Tablo 2.

\section{Çalışmaya katılan ve katılmayan öğrenci sayıları ve yüzdeleri}

\begin{tabular}{|c|c|c|c|}
\hline Sınıf & Çalışmaya katılan & $\begin{array}{l}\text { Çalışmaya } \\
\text { katılmayan }\end{array}$ & Toplam \\
\hline 1.sinif & $108(\% 97,3)$ & $3(\% 2.70)$ & $111(\% 100)$ \\
\hline 2.sinif & $85(\% 65,9)$ & $44(\% 34,1)$ & $129(\% 100)$ \\
\hline 3.sinif & $84(\% 67,7)$ & $40(\% 33,3)$ & $124(\% 100)$ \\
\hline Toplam & $277(\% 76,1)$ & $87(\% 23,9)$ & $364(\% 100)$ \\
\hline
\end{tabular}

Çalışmaya dahil olan öğrencilerin 108'ini (\% 39) birinci, 85 'ini (\% 30.7) ikinci ve 84'ünü (\% 30.3) üçüncü sınıf öğrenciler oluşturmaktadır ( $p>0.05)$. Cinsiyet açısından çalışmaya katılan öğrenci sayıları ve yaş ortalamaları Tablo 3'de verilmiştir.

Tablo 3.

Cinsiyet göre çalışmaya katılan öğrenci sayıları ve yaş ortalamaları

\begin{tabular}{|lllll|}
\hline Sınıf & Kız sayısı & Erkek sayısı & $\begin{array}{l}\text { Kılarda yaş } \\
\text { ortalaması }\end{array}$ & $\begin{array}{c}\text { Erkeklerde yaş } \\
\text { ortalaması }\end{array}$ \\
\hline 1.sınıf & 69 & 39 & $18,72 \pm 1,33$ & $19,03 \pm 0,87$ \\
\hline 2.sınıf & 51 & 34 & $19,33 \pm 0,84$ & $20,12 \pm 2,16$ \\
\hline 3.sınıf & 51 & 33 & $20,53 \pm 1,63$ & $21,27 \pm 2,28$ \\
\hline Toplam & 171 & 106 & $19,44 \pm 1,50$ & $20,08 \pm 2,05$ \\
\hline
\end{tabular}

Sınıflar arasında her iki cinsiyet açısından çalışmaya katılan öğrenci sayılarında ve yaş ortalamalarında istatistiksel fark yoktur $(p>0.05)$. Çalışmaya katılan toplam kı (171) ve erkek (106) sayıları arasında istatistiksel fark saptanmıştır $(p<0.05)$. Ankete verilen cevapların yüzdeleri Tablo'1 de yer almaktadır. Verilen yanıtlardan elde edilen en yüksek yüzdeler şu şekildedir: illk soruda katılımcıların \% 80.14 'ü diş yaralanmaları konusunda yeterli bilgi düzeyine sahip olmadığını belirtti. Yeterli bilgi düzeyine sahip olan katılımcıların \% 11.19'u bu bilgiyi "diş hekiminden" öğrendiği yanıtını verdi.

Katılımcıların \% 53.4'ü travma sonrasında diş hekimine "hemen" danışıması gerektiği yanıtını verdi. Katılımcıların \% 95.67'si "kırılan diş veya dişler varlığında ağrı olup olmamasına bakılmaksızın diş hekimine gidilmesi gerektiğini" belirtti. Kırılan diş parçasının bulunması gerekliliğine ise $\% 58.84$ katılımcı evet yanıtını verdi.

Katılımcıların \% 60.29'u yaralanmanın daimi dişte mi yoksa süt dişinde mi olduğunu ayırt edebileceklerini belirtti.
Daimi diş avulsiyonlarında katılımcıların \% 56.68'i dişin tekrar yerine yerleştirilmesi gerektiğini belirtirken, süt dişi avulsiyonlarında katıımcıların \% 63.9'u "dişin yerine yerleştirilmemesi” gerektiğini belirtti.

Katılımcıların \% 53.79'u avulse dişin soketine "hemen" yerleştirilmesi gerektiği yanıtını verdi. Yere düşmüş ve kirlenmiş bir dişin tekrar yerine nasıl yerleştirilmesi gerektiği sorusuna \% 71.48 oranında "steril serum fizyolojik ile yıkayıp yerine yerleştiririm" yanıtı alındı.

"Yerinden çıkmış bir dişi diş hekimine nasıl getirirsiniz?" sorusuna ise katılımcıların \% 29.6'sı süt içerisinde ve \% 23.47'si "çocuğun ağzı/tükürüğü içerisinde getirilmesi gerektiği” yanııını verdi.

"Diş yaralanmalarında tetanoz aşııının olup olmadığı önemli mi?" sorusunda katılımcıların \% 60.29'u "fikrim yok" yanıtını verdi.

\section{TARTIŞMA}

Travmatik dental yaralanmalar, hayatın her döneminde gözlenebilmesine rağmen, çocukluk çağlarında daha sıklıkla karşılaşılmaktadır. Bu yaralanmalarda, erken tanı ve tedavi oldukça önemlidir. Yaygın görülmesi nedeniyle, ebeveynlerin, öğretmenlerin, tıp fakültesi öğrencilerinin ve sporcuların dental travma bilgi düzeyleri çeşitli araştırmalarla değerlendirilmiştir. ${ }^{9-11,14}$ $\mathrm{Bu}$ çalışmada bir diş hekimliği fakültesinde travma dersi/eğitimi almamış birinci, ikinci ve üçüncü sınıf klinik öncesi diş hekimliği öğrencilerinin travma bilgi düzeylerinin bir anketle araştırıması amaçlanmış ve ankete verilen cevaplar arasında anlamlı farklılıklar tespit edilmiştir.

Anket sonucunda, ankete katımayı kabul eden kız öğrencilerin erkek öğrencilerden daha fazla sayıda olduğu görülmüş fakat kı ve erkek öğrencilerin verdikleri cevaplar 'önceki çalışmalarda olduğu gibi' $^{\prime, 10,12}$ ayrı ayrı ele alınmamıştır. Her sınıfta erkeklerin yaş ortalaması kızlardan daha yüksektir. Birinci sınıftan üçüncü sınıfa doğru yaş ortalamaları doğru orantıı olarak artış göstermektedir.

Ailelerin travmatik dental yaralanmalar hakkındaki bilgi düzeylerinin değerlendirildiği bir çalışmada, dental yaralanmalar konusunda daha önce hiç bilgisi olmayanların oranı \% 63.4 olarak bildirilmiştir. ${ }^{10}$ illkokul öğretmenleri üzerinde yapılan benzer bir çalışmada, dental yaralanmalar hakkında daha önce hiç bilgi almayan öğretmenlerin oranı \% 89.8 olarak bildirilmiştir. Bilgi sahibi olanların çoğunluğu, bu bilgiyi diş hekiminden öğrendiğini belirtmiștir. ${ }^{15}$ Çalışmamızda 
dental yaralanmalar konusunda yeterli bilgi düzeyine sahip olmayan öğrencilerin oranı \% 80.1'dir. Bilgisi olan öğrencilerin büyük çoğunluğu bu bilgiyi diş hekiminden öğrenmiştir.

Acil servislere travmatik dental yaralanmalarla başvuran hasta sayısı oldukça fazladır. Travmatik dental yaralanmalara acil müdahale oldukça önemlidir. ${ }^{16,17}$ Çalışmamızda öğrencilerin \% 53.4'ü diş yaralanmalarında diş hekimine "hemen" danışıması gerektiğini, \% 23.5'i birkaç saat içinde danışılması gerektiğini belirtmiştir. Tıp fakültesi son sınıf öğrenciler üzerinde yapılan, öğrencilerin dental travmaya yaklaşımlarının değerlendirildiği bir anket çalışmasında; dental travma sonrası diş hekimine danışılma aciliyetini "hemen" olarak işaretleyenlerin oranı \% 28.9, "birkaç saat içinde" işaretleyenlerin oranı $\% 31.6$ olarak bildirilmektedir9.

Travmatik dental yaralanmalarda en çok gözlenen yaralanma tipi kuron kırıklarıdır. ${ }^{2,18}$ Kuron kırıklarında geleneksel kompozit restorasyonlara bir tedavi alternatifi de kırılan parça mevcut ise defektin tamirinde hastanın kendi diş parçasının kullanılmasıdır. Bu uygulama ile daha iyi estetik, renk uyumu ve translusentlik sağlanabilmesi ve tedavinin daha kısa sürede tamamlanabilmesi mümkündür. ${ }^{19,20} \mathrm{Bu}$ durumla uyumlu olarak, çalışmamızda diş kırıldığında "kırık parçanın bulunması gereklidir" diyenlerin oranı \% 58.8'dir.

Özellikle okulda ve spor aktiviteleri sırasında karşılaşılabilen dişin soketten tamamen çıktığı (avulsiyon) durumlarda yapılacak acil müdahale, tedavi prognozu açısından oldukça önemlidir. ${ }^{21}$ Donaldson ve $\mathrm{ark}^{22}$, avulse dişlerin 15 dakikadan daha uzun süre kuru ortamda kalması sonucu, reimplantasyonun erken döneminde kök rezorbsiyonu gelişme olasııı̆ının arttığını vurgulamışlardır. Bu nedenle avulse dişlerin mümkün olan en kısa süre içerisinde soketine yerleştirilmesi önem arz etmektedir. Ankete verilen cevaplara göre öğrencilerin yarısından fazlası avulse olan daimi dişlerin reimplante edilmesi gerektiğini, avulse süt dişlerinin ise reimplante edilmemesi gerektiğini belirtmişlerdir. Reimplantasyonun "hemen" yapılması gerektiğini belirtenlerin oranı ise $\% 53.7^{\prime}$ 'dir.
Periodontal ligament ve sement hücrelerinin canlıı̆ının devam etmesi ve rejenarasyon açısından avulse dişlerin, süt, steril serum fizyolojik veya hastanın kendi tükürüğü içerisinde bulundurulması faydalıdır. ${ }^{23,24}$ Ebeveynler üzerinde yapılan bir çalışmada, dişi yıkamak veya taşımak için \% $50.84 \mathrm{su}$, \% 12.9 taze süt, \% 11.8 tuzlu su, \% 9.03 buzlu su, \% 7.9 antiseptik solüsyon ve \% 3.95 serum fizyolojik cevaplarının verildiği bildirilmiştir10. Çalıșmamızda saklama koşulu olarak avulse dişin \% 29.6 oranında süt, \% 23.4 oranında ise çocuğun yanağı/tükürüğü içerisinde getirilmesi gerektiği sonuçları alınmıştır.

Moran ve ark. ${ }^{21}$ ile Fouad ve ark. ${ }^{24}$ avulsiyon olgularında hastaya tetanoz aşısının uygulanması gerektiğini bildirmiştir. Çalışmamıza katılan öğrenciler, avulsiyon vakalarında tetanoz aşısının önemini büyük bir oranda (\% 65.7) bilmemektedir.

Çeşitli çalışmalarda ebeveynlerin, öğretmenlerin ve sporcuların dental yaralanmalar ve avulsiyon konusunda yeterince bilgi sahibi olmadıkları, bilgi sahibi olanların da bu bilgiyi diş hekimlerinden öğrendiği göz önüne alındığında ${ }^{10,11,14,15,25}$, diş hekimlerinin özellikle çocuk diş hekimlerinin, dental yaralanmalar konusunda toplumu daha fazla bilgilendirmesinin yararlı olacağı düşünülebilir. Bu konuda diş hekimleri tarafından verilebilecek eğitimler; travmatik dental yaralanmaların en az zararla atlatılmasına ve dişlere uygun rehabilitasyonların kısa süre içerisinde yapılabilmesinin yanı sıra tedavi maliyetlerinin azaltımasına da katkı sağlayacaktır.

\section{SONUÇ}

Elde edilen sonuçlar göstermiştir ki travmatik dental yaralanmalar konusunda "yeterli bilgi düzeyine sahip değilim" seçeneğini işaretleyen diş hekimliği öğrencilerinin oranı oldukça yüksek olmasına rağmen, ankete verilen cevapların tamamı değerlendirildiğinde, bu öğrencilerin travmatik dental yaralanmalar hakkında genellikle doğru yaklaşımlara sahip olduğu fakat bazı yanlış ve eksik bilgilerinin de bulunduğu sonucuna varılabilir. 


\section{KAYNAKLAR}

1. Andreasen, JO. Andreasen, FM. Essentials of traumatic Injuries to the teeth. 2nd ed. Copenhagen, Munksgaard and Mosby; 2000. P. 9-154.

2. Avşar A. 7-14 yaş grubu çocuklarda görülen travmatik yaraların incelenmesi. CÜ Diş Hek Fak Derg 2002; 12: 3743.

3. Altay N, Güngör HC. A retrospective study of dentoalveolar injuries of children in Ankara, Turkey. Dent Traumatol 2001; 17(5): 201-4.

4. Kargul B, Cağlar E, Tanboga I. Dental trauma in Turkish children, Istanbul. Dent Traumatol 2003;19(2):72-5.

5. Oliveira LB, Marcenes W, Ardenghi TM, Sheiham A, Bönecker M. Traumatic dental injuries and associated factors among Brazilian preschool children. Dent Traumatol 2007; 23(2): 76-81.

6. Hasan AA, Qudeimat MA, Andersson L. Prevalence of traumatic dental injuries in preschool children in Kuwait - a screening study. Dent Traumatol 2010; 26(4): 346-50.

7. Zaleckiene V, Peciuliene V, Brukiene V, Drukteinis S. Traumatic dental injuries: etiology, prevalence and possible outcomes. Stomatologija. 2014;16(1):7-14

8. Gassner R, Tuli T, Hächl O, Rudisch A, Ulmer H. Craniomaxillofacial trauma: a 10 year review of 9,543 cases with 21,067 injuries. J Craniomaxillofac Surg 2003; 31(1): 51-61.

9. Eden E. Kılınç G. Ellidokuz H. İzmir ilindeki iki tıp fakültesine devam eden son sınıf öğrencilerinin dental travmaya yaklaşımları. DEÜ Tıp Fak Derg 2011; 25(1): 31-7.

10. Ozer S, Yilmaz El, Bayrak S, Tunc ES. Parental knowledge and attitude regarding the emergency treatment of avulsed permanent teeth. Eur J Dent 2012; 6(4): 370-5.

11.Tozoğlu Ü, Şahin H. Ebeveynlerin dental avulsiyon ve tedavisi hakkındaki bilgilerinin değerlendirilmesi. Atatürk Üniv Diş Hek Fak Derg 2006; 16(3); 19-22.

12. Chandukutty D, Peedikayil FC, Premkumar CT, Narasimhan D, Jose D. Awareness of Dental Trauma Management among School Teachers of Kannur, Kerala, India. J Clin Diagn Res. 2017;11(2):ZC08-ZC12.

13. Nourwali IM, Maddhar AK, Alsaati BH, Alhazmi RA, AlAyoubi SM, AlHarbi SS. Emergency management of dental trauma: a survey of public knowledge, awareness, and attitudes in Al-Madinah Al-Munawwarah. Clin Cosmet Investig Dent. 2019;11:279-284. Published 2019 Aug 27.

14. Keçeci AD. Sporcularda dental travma. Egzersiz 2007: $1(1) ; 6-15$.

15. Bayrak S, Tunc ES, Sari E. Evaluation of elementary school teachers' knowledge and attitudes about immediate emergency management of traumatic dental injuries. Oral Health Prev Dent 2012; 10(3): 253-8.

16.Sari ME, Ozmen B, Koyuturk AE, Tokay U, Kasap P, Guler D. A retrospective evaluation of traumatic dental injury in children who applied to the dental hospital, Turkey. Niger J Clin Pract 2014; 17(5): 644-8.

17. Kaul R, Jain P, Saha N, et al. Evaluation of knowledge, awareness, and attitude toward emergency dental trauma management among the school teachers of Kolkata. Indian J Dent Res. 2017;28(6):595-603.
18.Petrović M, Kühl S, Šlaj M, Connert T, Filippi A. Dental and General Trauma in Team Handball. Swiss Dent J. 2016;126(7-8):682-6.

19.Karakaya Ş, Özer F. Kırılmış bir anterior dişin kendi kırık parçası ile restore edilmesi: 2 yıllık vaka raporu. OMÜ Diş Hek Fak Derg: 2004; 5 (1): 30-4.

20.Singh TK, Passi D, Aggarwal S, Mohan S, Sharma A, Gupta U. Esthetic management of complicated crown fracture of three permanent maxillary teeth by grout technique -A case report. J Family Med Prim Care. 2019;8(7):253841.

21. Moran I, James M, Cook W, Perry M. Tooth avulsion. BMJ 2016; 25; 353: i1394.

22.Donaldson M, Kinirons M,J. Factor affecting the time of onset of resorption in avulsed and replanted teeth in children. Dent Traumatol 2001; 17: 201-5.

23. Huang SC, Remeikis NA, Daniel JC. Effects of long-term exposure of human periodontal ligament cells milk and other solutions. J Endod 1996; 22: 30-3.

24. Fouad AF, Abbott PV, Tsilingaridis G, Cohenca $\mathrm{N}$, Lauridsen $\mathrm{E}$, Bourguignon $\mathrm{C}$, et al. International Association of Dental Traumatology guidelines for the management of traumatic dental injuries: 2. Avulsion of permanent teeth. Dent Traumatol. 2020 May 27. Epub ahead of print.

25.Pacheco LF, Filho PFG, Letra A, Menezes R. Evaluation of the knowledge of the treatment of avulsions in elementary school teachers in Rio de Janeiro, Brazil. Dent Traumatol 2003; 19: 768.

Yazışma Adresi:

Bilal ÖZMEN

Ondokuz Mayıs Üniversitesi

Diş Hekimliği Fakültesi Pedodonti AD.

Samsun, Türkiye

E Posta: bilalozmen@hotmail.com 